\title{
POST-TRAUMATIC PAIN AND THE CAUSALGIC SYNDROME
}

\author{
BY
}

\section{J. DOUPE, * C. H. CULLEN and G. Q. CHANCE}

From the Winwick E.M.S. Hospital, Nr. Warrington

\section{(RECEIVED 14TH APRIL, 1944)}

IT is not uncommon, especially in wartime, to be faced by patients complaining of persistant severe pain in the hand or foot following an injury to a limb, despite the absence of apparent cause. It is with such cases that the present paper is concerned. Excluded from consideration are cases in which post-traumatic pain arises from tender neuromata or obvious vascular abnormalities.

Weir Mitchell (1872) dealing particularly with injuries involving nerves used the term causalgia for this condition, and though describing many examples that have become classical he did not rigidly define the term. Indeed Homans (1939) suggests that a considerable number of states have been at one time or another included under this term and such a view is supported by ideas developed elsewhere (Doupe and Cullen 1943). On the other hand, it would seem that cases of causalgia have been described under a variety of other names. This tendency to dispersion in the literature has been noted, both by Homans (1939) and de Takats (1943), and they have been tempted to counteract it by grouping many of these conditions together. In Table $I$ it will be seen that there is a disparity in the conditions so grouped by these two authors and that the cause of this disparity appears to lie not only in the redundant terminology but in different conceptions of the genesis of the condition: Homans stressing the part played by reflex arterial spasm while de Takats is impressed by the element of vasodilatation.

TABLE I

Homans, 1939

Reflex Arterial Spasm.

Chronic Segmental Arteria Spasm.

Causalgia.

Causalgia.
Reflex Dystrophy of the Pudeck's Atrophy. Extremities.

Trophic Edema.

Traumatic Osteoporosis.

DE TAKATS, 1943

État Physiopathique of Vulpian. Causalgia. Osteoporosis.

Peripheral Acute Trophoneurosis.

Grouping of Terms applied to Post-Traumatic States.

The confusion caused by using the term causalgia for different conditions and by describing cases of

* Working on behalf of the Medical Research Council. causalgia under different names indicates the need for the classification and segregation of different post-traumatic painful states. However, a classification, no matter how sorely needed, cannot be satisfactory so long as it is based on symptoms. As it would be over ambitious to attempt to define the post-traumatic states themselves it is the intention here merely to distinguish the different varieties of pain and to speculate as to their cause. In this way the value and the limitation of the symptom of pain in differentiating the various post-traumatic states will become evident.

In this paper a group of patients with a variety of post-traumatic pains will be presented and a special attempt will be made to define one particular type. This for valid historical reasons will be called the causalgic syndrome and despite the rules against tautology, the cases will be said to suffer from causalgic pain. Personal considerations suggest that this usage is free from the dangers of spurious finality which are inherent in a diagnosis of " causalgia." Cases of other than the causalgic syndrome have been included as a means of contrast and to illustrate the three most common types of posttraumatic pain. As the group of cases has been selected for this purpose it does not show the relative incidence of the particular syndrome. The description of causalgic pain may best be accomplished by presenting a theory of the mechanism by which it is produced. In developing the theory one of several manifestations could be used as a starting-point and it might seem that the objective findings would prove the most satisfactory. The objective findings consist of changes in vascularity and nutrition and it will be well to consider how far a study of them can aid in the present endeavour.

The vascular changes have been studied most recently and most thoroughly by Miller and de Takats (1942), who find, in agreement with others (Leriche and Fontaine, 1929; Lewis, 1942), that the blood-flow is greater in the painful than in the normal contralateral extremity. The importance of such observations naturally depend on the ability to interpret them. The blood-flow to normal digits may change a hundred-fold or more (Wilkins et al., 1938), while the factors affecting the flow are too numerous to detail. Lewis and Pickering (1931-33) 
have studied some of these and find that differences in use, posture, and temperature can cause unequal flows in normal limbs. Therefore, it may be thought that numerous interpretations could be placed on the finding of an increased flow in an injured extremity which, because of œdema, lack of use and general disturbance of function, is hardly comparable to the normal. The number of possible interpretations is also increased if there is a coexisting nerve injury. This difficulty of interpretation is demonstrated by the charts of skin temperatures in Figs. 2, 4, 6, and 8, which confirm the findings of an increased blood-flow in the affected extremities, but seem rather to ask for an explanation than to suggest one. Thus it is concluded that the finding of an increased blood-flow or an increased oscillometric index does not contribute to the understanding of the primary mechanism of the causalgic syndrome. This conforms with the opinion of White and Smithwick (1943), who state: "All that emerges from these theories as reasonably certain is that abnormal vasomotor activity usually accompanies pain."

The nutritional state of the extremity has caused comment since the first description of glossy fingers by Paget (1864). Mitchell et al. (1864a) were particularly impressed by these changes, but note that pain may be present without the cutaneous disorder. Lewis (1942) remarks that some of the changes may be due to disuse while reference to Hurst's (1940) description of the results of hysterical palsies suggests that many of the features may be so explained. It is to be noted that case D. P. was a well-marked example of glossy skin and curved nails, yet he was free from pain. Pollock and Davis (1933) report similar experiences. Thus the exact significance of the skin-changes is debatable.

Besides changes in the skin, changes have been described in the bones and these are so striking that they have achieved pride of place in some terminologies, viz., the post-traumatic painful osteoporosis of Leriche and Fontaine (1930), Fontaine and Herrmann (1933), and Herrmann et al. (1942). It would appear that these authors regard the bonechanges as being diagnostic of this condition, but the view is gaining ground that the spotty atrophy is a non-specific reaction of bones and de Takats (1943) emphasizes that the diagnosis cannot be made by X-rays alone. This point is illustrated by cases W. C., D. P., and F. B. in the present series, who showed well-marked osteoporotic changes yet had slight or no pain. Delorme (1917) has also presented evidence for this view. To many (Noble and Hauser, 1926; Gurd, 1934; Nonne, 1902; Sudeck, 1938; Kienbock, 1901; and Turner, 1936) the porotic picture of the bones in the acute stage has suggested that it is produced by nervous action. That such an explanation is not tenable is shown by cases R. D., W. A., and D. P., in which the course of the bone atrophy was not altered by the degeneration of the nerves. The ulnar nerve was completely divided in the first two cases, the median and radial in the last. It seems that the disturbances of bone, like those of the skin, may be present with or without pain, with or without a nerve supply. Therefore, they fail to give a clue to the primary disturbance in the causalgic state.

At first sight it might appear unsatisfactory to be forced to depend upon a subjective symptom such as pain for the basis of investigation. Nevertheless, pain is the central feature of the causalgic syndrome and as such would in any event merit consideration, but so unique are its features that they command attention. These features have been exceptionally well summarized in the publication of the Medical Research Council (1920) which states: "Causalgic pain has the following characters. It is (1) spontaneous; (2) hot and burning in character, intense, diffuse, persistent, but subject to exacerbations. (3) Causalgic pain can be excited by stimulation, which does not necessarily produce a physical effect on the limb. Emotional excitement usually aggravates the pain and brings on a paroxysm. (4) It tends to lead to profound changes in the emotional state of the patient." To these may be added a fifth characterisitc, that of relief by sympathetic block. This combination would appear to permit of only one explanation and for the proper evaluation of this explanation the following statements should first be considered.

(A) In certain conditions nerve impulses can alter the excitability of adjacent fibres. This has been shown by Katz and Schmitt (1942). Moreover, Young (1944) has found evidence that the substance of neighbouring axons may sometimes fuse, at least temporarily, during regeneration, while Speidel (1935) has observed the actual occurrence of such a fusion in his frog preparations.

(B) Sympathetic fibres to the digital vessels and to the palmar and plantar sweat glands are actuated by emotional stress. Sympathetic fibres are also brought into activity by the needs of thermoregulation, vasoconstrictor fibres in case of undue heat loss, sudomotor fibres in case of undue heat gain. Pilomotor fibres are similarly actuated by a variety of stimuli, some of which include cold, emotion, micturition, defæcation, and certain forms of cutaneous stimulation.

These' two statements forcibly suggest the possibility that causalgic pain is due to the activation of sensory fibres by sympathetic impulses. In support of this proposition it will be found that it furnishes an explanation for the various qualities of causalgic pain.

(1) The pain would seem to be spontaneous in that it would be in part related to the needs of thermoregulation rather than to any external or local influence. Due to alternating activities of the sudomotor and vasoconstrictor fibres pain would be present both when the subject is hot and when he is cold. It might be expected, however, that changes in intensity of the spontaneous pain would be produced by changing the need for heat conservation to that for heat dissipation. The four attempts that were made to demonstrate this resulted in the records shown in Fig. 2, Exps. 1 and 2; 
Fig. 6, Exp. 1; and Fig. 8, Exp. 1. In these experiments with the exception of that reported in Fig. 6, Exp. 1, the patients reported a diminution of pain when release of vasoconstriction was occurring and before sweating was observed. These results, while suggestive, must be interpreted cautiously, not only because the amount of pain cannot be accurately assessed, but because the pain would be expected to vary with the "feeling tone" which is itself altered by changing from the cold to the hot state.

(2) The pain would be diffuse, i.e. not well localized, and if pain and temperature fibres being small were particularly sensitive to the temporal configuration of the action currents of the sympathetic fibres, the sensation would be described as hot and burning. Moreover, the sensation would be foreign to previous experience, and this would account for the great difficulty found in describing its nature (Cases F. L. and M. S.). It will be noted that in cases E. M., A. B., W. A., and W. E. it was described as a burning or searing feeling.

(3) Emotional excitement or stimulation which does not necessarily produce an effect on the limb would cause pain because of the associated discharge in sympathetic fibres. This characteristic of causalgic pain which is so unique is easily demonstrated by the simple procedure of asking the patient to take a deep breath. In cases T. P., A. B., M. S., and W. E., to whom this was done, a momentary exacerbation of the pain was experienced, and this can be related to the increased activity of vasoconstrictor fibres (Bolton et al., 1936) and sudomotor fibres (Carmichael et al., 1941) caused by a deep breath. It is to be noted that another type of stimulation, namely, a pin-prick, anywhere on the body has been shown to cause a similar sympathetic discharge (Stürup et al., 1935), and this likewise produces the pain. In this instance the time relations are ascertainable, and it has been found (Fig. 1) that the exacerbation of pain commences 1-2 seconds after the pin-prick, i.e. coincident with the discharge rather than with the vasoconstrictor or sudomotor activity. Such a phenomenon no doubt accounts for much of the hyperæsthesia found when the causalgic limbs are examined which contrasts with the liberty with which some patients can themselves touch the parts. In fact, in cases T. P. and E. M. the mere apprehension of being touched was associated with a notable increase in the pain. Moreover, causalgic pain differs from other pains in that it may be aggravated rather than relieved by having the attention firmly focussed elsewhere. This can be seen in cases T. P., E. M., and W. A., in whom it may be thought that the diversions of the cinema were accompanied by emotional excitement with consequent sympathetic discharge leading to an increase in pain.

(4) The tendency to profound mental changes would be the least surprising consequence of pain produced in this fashion. The patient would be caught in a cycle of peculiar viciousness, pain, and worry leading to sympathetic discharge, causing further pain and worry, a train of events which might well lead the unfortunate sufferer to seek solace by the most desperate measures. However, some of the indications of mental disturbance, such as a desire for solitude and phobias directed towards noises, etc., can be explained without hypothecating any mental derangement. Thus cases T. P., E. M., F. L., and A. B. preferred to be left alone and to lie cuddled in their beds in a quiet corner of the ward because social contacts inevitably led to pain. It is noteworthy that these reclusive traits disappeared immediately the pain had been stopped by sympathectomy. Likewise, the fear of noises which superficially would appear quite unreasonable is explained by the sympathetic discharge caused by this stimulus (Stürup et al., 1935). It may also be postulated that the curious apprehension of dry contact elsewhere on the body (cases A. B. and M. S.) is connected with sympathetic discharges possibly in pilomotor fibres. Moreover, the soil is prepared for the cultivation of a variety of conditioned responses, for once a situation becomes associated for any reason in the patient's mind with an increase in the pain, recurrence of the situation will cause apprehension which in turn will induce a sympathetic discharge producing the feared pain.

(5) It is obvious that a sympathetic block would abolish causalgic pain and the efficiency of this measure is seen in all the cases of the causalgic syndrome. Three other explanations for the phenomenon may be considered. (1) Lewis (1942) has suggested that the vasodilatation so produced is the cause of the relief. This, however, is unacceptable because vasodilatation produced in other ways, i.e. reflexly, does not abolish the pain (cases T. P., E. M., A. B., and M. S.). (2) de Takats (1943) considers that it is efficacious because it causes arteriolar dilatation which is associated with a capillary constriction and thus corrects what he claims is the primary disturbance. In support of this he mentions that the pulsating pain is abolished by suprasystolic compression of the limb. Such a procedure had no effect on the pain in case A. B., and cases with pain pulsating in rhythm with the heart have not been encountered. This explanation, therefore, does not seem satisfactory for the causalgic syndrome, but there may well be other members of the group of the post-traumatic pains to which this or some related theory is applicable. (3) Middleton and Bruce (1933-34) considered that pain is relieved by sympathectomy because the afferent pain pathways are cut. Despite the lack of evidence for afferent fibres in the sympathetic nerves to the limbs this hypothesis was tested in case T. P. by a spinal anæsthetic which blocked the posterior root inflow from the feet as shown by the loss of sensation, but did not affect the sympathetic outflow as shown by the maintained low skin temperature (Fig. 2, Exp. 4). This resulted in a complete cessation of pain showing that the segmental inflow was requisite for the appreciation of causalgic pain. Therefore, in default of other explanations and because the present one seems to fit the case so aptly it is considered that sympathectomy causes relief 
by blocking the efferent impulses which would otherwise stimulate the sensory nerves.

So far this line of reasoning has encountered no pitfalls, but the observation of Tinel (1918) that the pain is relieved by blocking the nerve below the lesion appears to present an impasse. In reality this discovery forms the basis on which some of the causalgic states following nerve injuries can be brought into line with those which follow injuries not primarily involving the nerves. In cases such as A. B., M. S., and W. A., where nerve block below the level of the injury relieved the pain, it must be presumed that the conjunction of the sympathetic fibres and the sensory fibres occurs in the periphery. Nor is it difficult to imagine how certain circumstances of œdema and ischæmia could impair the nutrition of the terminal nerves so that through defective insulation or actual union of the fibres cross stimulation could occur. It is a defect of the present series of cases that it contains no instance of the causalgic syndrome following injuries other than those involving nerves, though it must be admitted that a review of cases, such as that of A. B., indicates that there was little evidence of primary nerve involvement. Retrospection suggests that a nerve lesion had been presumed in order to account for the pain. In other cases of injuries to the nerves the site of the transference of the impulses lies at the place of injury, as shown by the failure to relieve the pain by nerve block below the lesion (cases T. P. and E. M.). This would appear of necessity to be the condition underlying the causalgic pains of phantom limbs (case W. E.).

It is obvious that this thesis is open to clear-cut proof or disproof by the crucial experiment of stimulating the distal end of the sympathetic nerves supplying the causalgic part. In practise the procedure is difficult, due to the complications introduced by the anæsthetic. It was attempted in two cases, and faradization of the end of the chain evoked expressions of pain which were too vaguely localized to have great importance attributed to them.

It has been pointed out above that the objective signs of the causalgic syndrome are susceptible to so many explanations that they can be made to support nearly any theory. Therefore, it is only just worth noting that they are not incompatible with the present explanation. Thus, the stimulation of the afferent fibres would cause anti-dromic vasodilatation and account for the observed increase in blood-flow. The pink shining skin might well be simply an expression of disuse plus vasodilatation.

The changes in the bones have been discussed above and are considered to be a non-specific reaction common to many different states, not all of which are painful. Another objective phenomenon sometimes encountered is hyperhydrosis. This is difficult to explain by any theory, but it is to be noted that it is not restricted to the causalgic syndrome (case D. P.). It may be that it is simply an expression of the hypersensitivity of partially denervated glands, but in any case it is not an integral part of the syndrome as it was absent in cases T. P. and E. M.

Several therapeutic procedures require mention because of their bearing on the present theory. Mumford (1938) has reported that a small amount of X-ray treatment to the hand or foot gave great relief of pain in a condition called acute osteoporosis. He suggests that the radiation may have some effect on the nerves. This therapy might therefore have been expected to benefit patients in whom a tenous junction between the sympathetic and sensory fibres was thought to be located at the periphery of the limb (cases A. B., M. A., and W. A.). In other cases (T. P. and E. M.) in which the connection was presumed to exist in the nerve trunk this treatment would be of no avail unless directed to this site. It will be seen that no benefit resulted in this series with the possible exception of case W. A. and it should be mentioned that Mumford's cases were not typical of the causalgic syndrome. This bid to obtain support for the present theory must therefore be counted a failure.

Experience of the value of periarteral sympathectomy in patients with the causalgic syndrome has been limited to case W. A. to whom no benefit accrued.

Repeated severe blistering was found by Mitchell et al. (1864b) to be beneficial in some cases, and it is not impossible that this therapy is non-specific in that it would cause a profound disturbance of the tissues leading to a disruption of any painful process that might exist. No cases have been treated by this method.

Finally, in this discussion of the mechanism of causalgic pain reference must be made to two unexplained phenomena. These are the variable time of onset of the pain and the tendency for the pain gradually to lessen. Both these must depend on the nature of the link between the sympathetic and the sensory fibres. Inasmuch as this link is a mere postulate to fit the facts, nothing in reality being known about it, there are no grounds on which to base a discussion. For the sake of clarity it should be pointed out that the long delay in onset in case W. A., is referable to the temporary abolition of conduction in the nerves.

\section{Observations}

The foregoing comments supply a key to the understanding of the cases about to be reported. In most instances the significance of the observations will be too apparent to require formal interpretation. The terminology is discussed in the following section.

The methods used to obtain the experimental observations are described in a former paper (Doupe, 1943). To obtain the X-rays a standard technique was used, and with few exceptions the normal and affected limbs were simultaneously exposed. In the reproductions the normal has been omitted in some instances to save space. X-rays were taken, when possible, at intervals of one to two months, but only the more significant are shown here. All cases have 
been followed for at least four months after sympathectomy.

\section{T. P., aged 23. A Case of the Proximal Causalgic} Syndrome.

He was admitted 9 months after incurring a gun-shot wound of the left popliteal space at El Alamein. A suture of the left external popliteal nerve had been performed in the third month.

He complained of pain and tenderness of the left foot located chiefly in the sole at the base of the outer toes. The pain commenced 3 to 4 days after the injury and rapidly became worse so that on the fifth day it was at its height and he required morphine for 5 to 6 weeks. Thereafter it somewhat diminished and following the operation in the third month he was able to sleep. In the next few months further improvement occurred, but for the last three months the condition had been stationary. The character of the pain had not altered, the sensation being that of someone tearing the toes apart. At times there were periodic exacerbations described as burning stabs occurring every 5 to 6 seconds and lasting about 2 seconds. As to aggravating factors, he had no memory of the first few months, but stated that now the tearing pain was nearly absent when lying quietly, but that he got a spasm of pain if the bed was unexpectedly jarred or if there was a sudden noise. When asked if he went to the cinema, he replied that he didn't because if there was anything exciting like "people climbing up cliffs" the pain was made worse. The pain tended to be worse in damp weather, but was immediately relieved by putting the foot in warm water. It was also aggravated by a dependent position of the leg.

Examination showed the signs of a complete lesion of the lateral popliteal nerve. The muscles supplied by the medial popliteal nerve contracted with moderate strength. Sensation was difficult to test because he resented any disturbance of the foot. He stated that the tenderness now was not so severe as at first, but he still could not tolerate any pressure. Slight touches in the distribution of the medial popliteal nerve were felt as painful, while pin-pricks were very painful. These modes of stimulation produced aggravation of his usual type of pain, and he said that he felt the pain when he saw anyone about to touch the foot. Questioning revealed that the pain caused by a threat to touch the foot did not come on at once and estimations of the delay showed this to be in the region of 1 to 2 seconds. A pin-prick on the arm, a sudden noise, or a deep breath also caused the pain

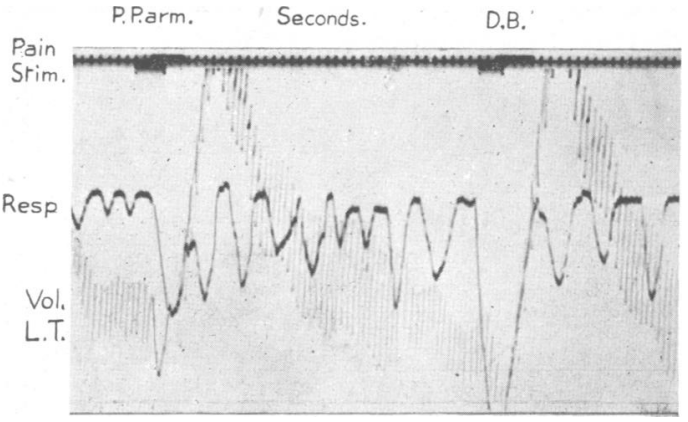

FIG. 1.-Plethysmographic record of T.P. (method of Bolton et al., 1936). The upper signal activated by the patient indicates pain felt in the right foot. The lower signal indicates the stimuli, the first being several pinpricks on the arm and the latter a deep breath. Time is in seconds. In the respiratory tracing a downstroke indicates inspiration. The volume of the left great toe is being used to show vasoconstrictor activity. An upward movement of the tracing represents a decrease in volume.

in the foot after a delay of 1 to 2 seconds (Fig. 1). $\mathrm{He}$ stated that he could handle the foot himself much more freely than if it were done in a similar way by another person.

The appearance of the foot was not strikingly abnormal. It tended to become œedematous if allowed to hang down for long periods, and the skin of the sole was free from callosities. The temperature of the foot (see charts in Fig. 2) tended to be slightly above those of the normal foot even after prolonged exposure. The pulse of the posterior and anterior tibial arteries of the two feet were similar to palpation. There was considerable restriction of movement at the ankle and at all the joints of the foot. $\mathrm{X}$-rays of the two feet showed a well-marked decalcification of the affected foot, suggestive of the latter stages of Sudeck's atrophy (Fig. 3).

At the tenth month, i.e. 1 month after admission, the condition being unchanged, the wound was explored. The state of the lateral popliteal nerve required excision of a length of $5 \mathrm{~cm}$. and re-suture was performed. The medial popliteal nerve was found to be the seat of a slight

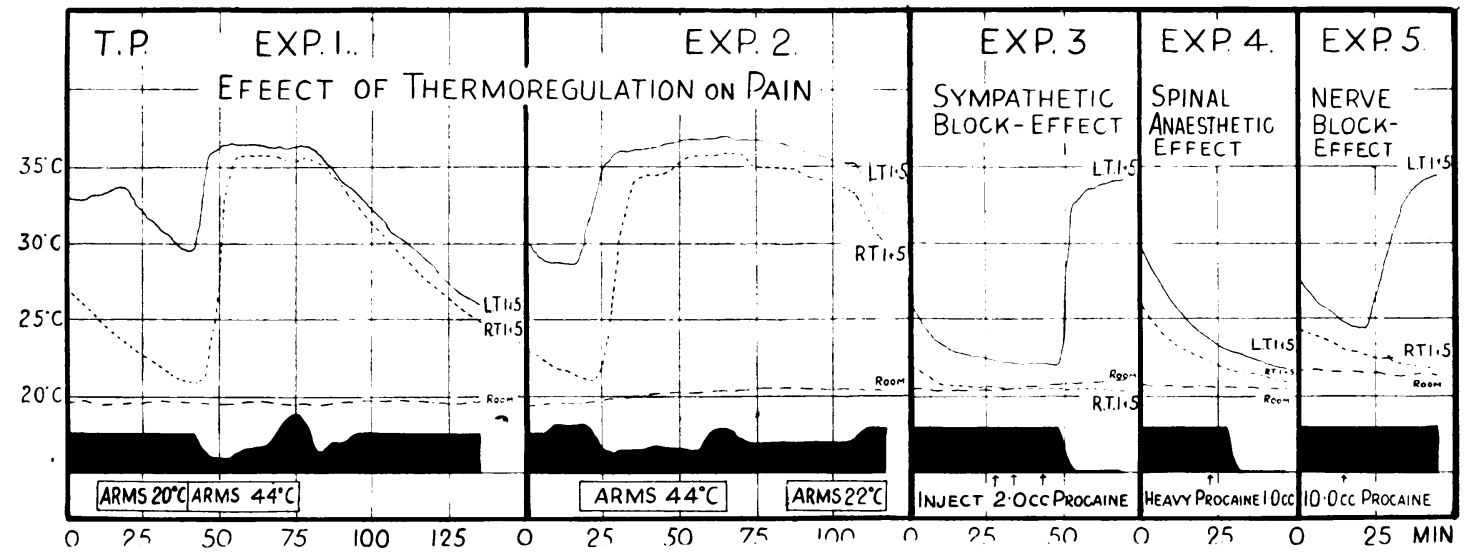

FIG. 2.-Temperature charts of subject T.P. In this and similar figures the following conventions are used. The continuous line represents the temperature of the tip of the affected digits, the broken line that of the contralateral digits and a broken line with dots that of the room. In those instances in which the affected digits behaved discordantly a dotted line is used to represent one of them. The symbols LT 1 and 5, etc., denote the left first and fifth toes, etc. Temperature readings were taken at all sites at 3-minute intervals. The filled area represents the degree of pain as assessed from the patient's statements at 5 to 10-minute intervals in relation to the pain at the beginning of the experiment. Experimental procedures are indicated on the face of the charts. Thus, in Exp. 1 the arms were put in water at $20^{\circ} \mathrm{C}$. for the time indicated by the block, and were then transferred to water at $44^{\circ} \mathrm{C}$. The arrows indicate the times of injections of the amounts of the anæsthetic specified. 


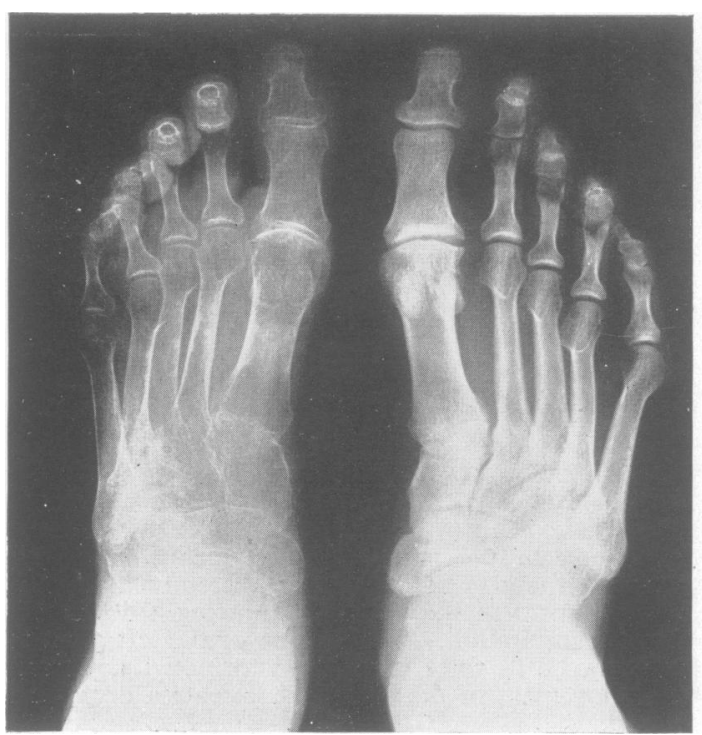

Fig. 3.-X-ray of both feet of subject T.P. taken 12 months after injury.

fusiform thickening about $3 \mathrm{~cm}$. in length, which was adherent to scar tissue and to the neuroma on the lateral popliteal nerve. Faradic stimulation of this area produced the pain in the foot. Neurolysis was performed and the nerve placed in a bed deep in the popliteal space. The pain was in no way affected by this operation, and consequently when the plasters were removed a course of X-ray therapy was given to the foot. This also had no effect and 6 weeks later the following investigations were performed:-

1. Block of the left lumbar sympathetic chain (Fig. 2, Exp. 3) relieved all pain and most of the tenderness. To rule out a psychogenic element the procedure was repeated, but the chain was not blocked, as shown by the maintenance of vasoconstriction, nor was the pain in any way affected.

2. A spinal anæsthetic blocking the segmental inflow as high as L. 3 completely abolished the pain (Fig. 2, Exp. 4).

3. Block of the post-tibial nerve near the ankle had no effect on either the spontaneous pain or on that induced by loud noises, though the whole foot was anæsthetic and could be handled at liberty (Fig. 2, Exp. 5).

These observations indicated that the pain was arising at the site of the nerve lesion, was being conducted by the segmental posterior roots, and that intact sympathetic pathways were requisite for the production of pain.

On the fifteenth month after the injury a left lumbar sympathetic ganglionectomy was performed. This resulted in complete relief from pain and the hyperæsthesia of the foot was replaced by a mere alteration of sensation.

\section{E. M., aged 36. A Case of the Proximal Causalgic Syadrome.}

Admitted four months after a bomb splinter wound of the left axilla. The notes state that the wound was explored 14 hours later, and that the brachial artery was found to be thrombosed while the ulnar and median nerves were slightly bruised. The pulse returned at the end of 2 months, the wound was infected and healing was not complete for three months.

Pain had been the outstanding symptom from the moment of injury. It started within two minutes and increased to such a peak in 2 to 3 hours that he begged to have the arm removed. The pain at first was located in the fingers, but in the next two hours spread to both the palm and the thumb. It was restricted to the palmar aspect and the hand was much swollen; since then the pain had not changed though he thought that he was getting accustomed to it, as at first he required much morphine. He had learned that keeping the hand absolutely still and avoiding excitement mitigated the pain. The pain was variously described as a crushing burning, and as though a burned area were being held in front of the fire. Sudden bursts of pain were indescribable. Factors altering the pain were various. The weather did not seem to affect it, but any noise, such as a slamming door or the sound of aeroplanes, was extraordinarily painful. Low-flying aeroplanes made him nervous, and he could not say whether this was because of the pain or for some other reason. Thus he had become accustomed to flinch whenever a fast-moving truck went by, but when this occurred while his sympathetic chain was blocked he was at a loss to understand why he flinched until he remembered that he usually had pain at such times. When asked about the cinema he said he never went, and in explanation he described how he had gone to see the Marx Brothers in "Big Store" and found that the scenes of singing and dancing gave him pleasure, but when a mad chase on bicycles and roller skates was portrayed, he had to close his eyes to try to escape the pain that the excitement produced. The only time that he was really free from pain was if he should chance to wake up very slowly and then his hand would be quite painless until he was disturbed. The pain was made worse by putting the hand in warm water and somewhat relieved by putting it in cold. He considered that the hand was unusually dry, and so kept it covered with a moist cloth and felt more comfortable this way, though at first even the water was unbearable and he used vaseline.

Examination, which was difficult, revealed partial lesions of the median and ulnar nerves, as shown by moderate power in the long flexors of the wrist and fingers, but absent power in the long flexor of the thumb and of all the intrinsic muscles. Appreciation of light touch and pin prick was lost in the distribution of the median nerve, but was present in that of the ulnar. The patient said that this had but recently returned. Apprehension was so great that at first there appeared to be hyperæsthesia of the whole hand, any approach to it causing withdrawal with expressions of pain. Later, however, when confidence was gained it was found that when the eyes were shut neither light touch, pin prick, nor heavy pressure could be felt on the index finger, though when the eyes were open these caused great pain. He was able to touch the hand much more freely than he would allow others to do.

He stated that the fingers were always warm and pink, and two experiments recording skin temperatures for 45 minutes showed that the blood-flow to the little finger was always much greater than that to the normal contralateral fingers, while the flow to the index finger was variable (Fig. 4, Exp. 1 and 2). The skin of the palm was thin and atrophic. The median area was anhydrotic, while the ulnar area sweated, but not excessively.

$\mathrm{X}$-rays on admission and three months later showed a progressive decalcification of the Sudeck type (Fig. 5).

Other investigations showed:-

1. Block of all the nerves at the wrist did not reduce the pain, but in some way altered its character.

2. Block of the sympathetic chain gave complete relief (Fig. 4, Exp. 3).

3. No relief was experienced by a course of X-ray treatment to the hand, while a similar course of treatment direct to the nerve trunk at the sight of the lesion likewise caused no change in the pain.

Sympathectomy was therefore advised, and in the seventh month an operation was performed by the posterior approach and a segment of what appeared to be the sympathetic chain was removed. Inasmuch as all concerned were convinced of this it was somewhat disconcerting to find that the patient was only partially 


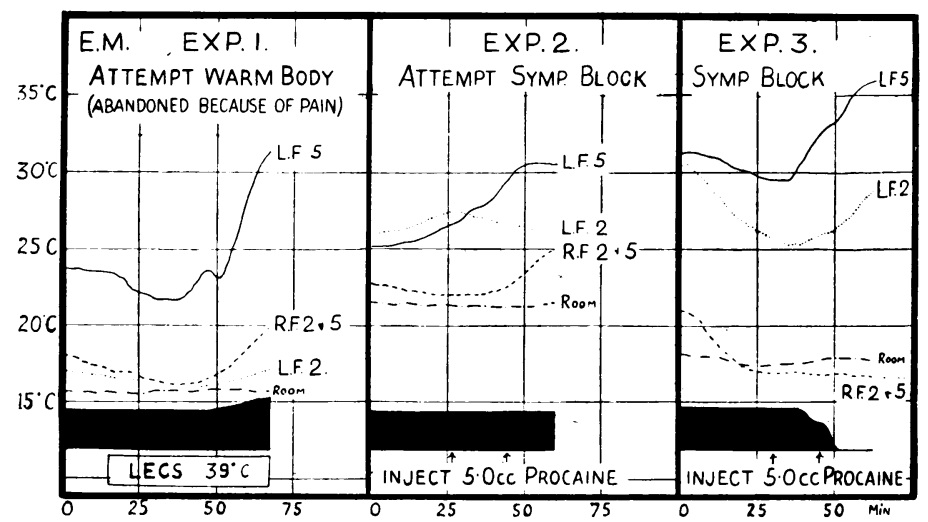

Fig. 4.-Temperature charts of subject E. M. Conventions as in Fig. 2.
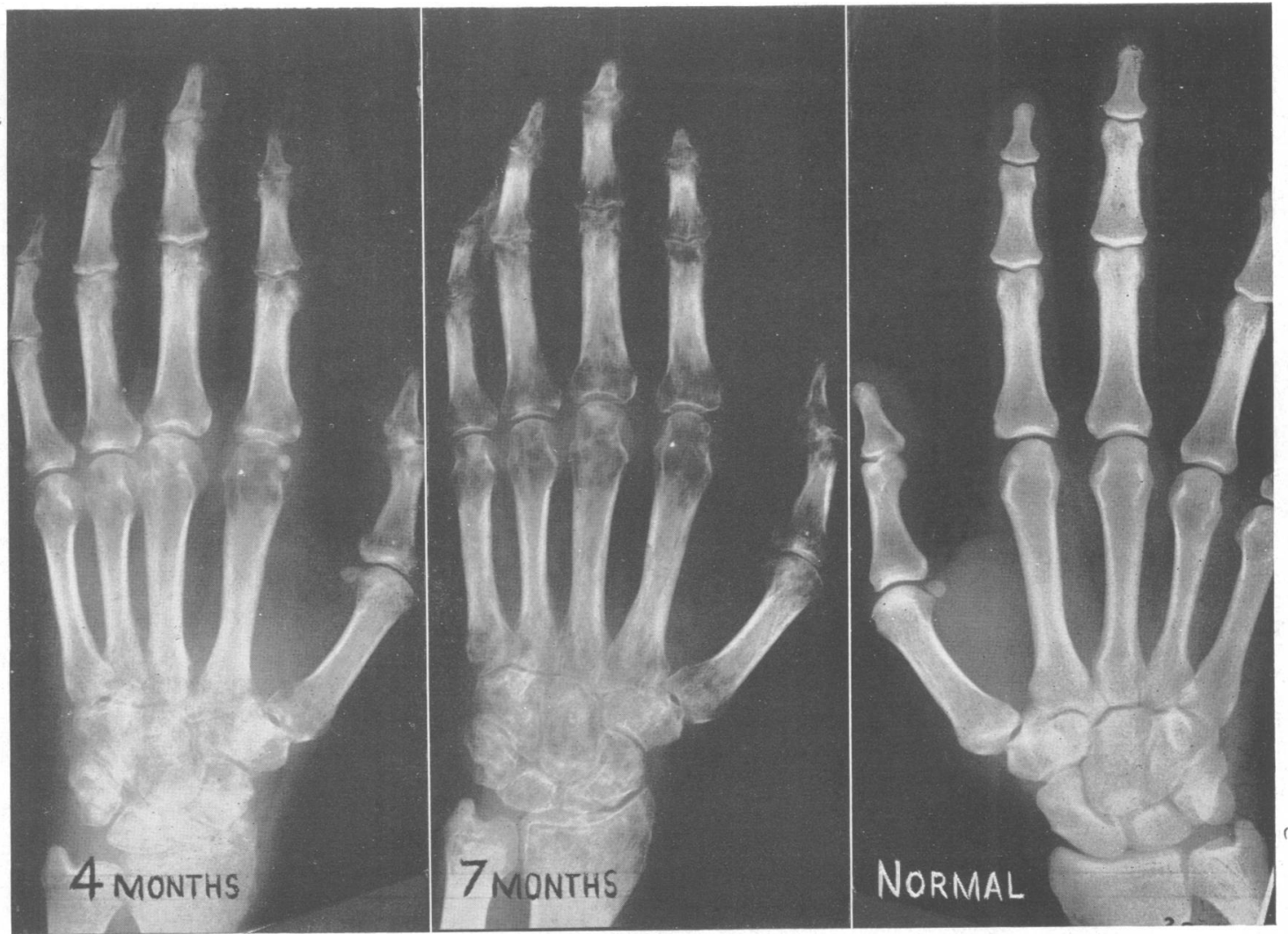

Fig. 5.-X-rays of subject E. M. taken 4 and 7 months after injury. The normal right hand shown at the right was taken at the same exposure as the left hand at 4 months.

relieved for 2 to 3 days and thereafter suffered his usual torments. Clinical opinion at this time wavered between calling the patient a hysteric and deriding the method of therapy. These points are mentioned to stress the fact that operation plus other forms of strong suggestion did not avail to convince him that he had no pain. It was then found that sweat was present on the face and arm of the operated side, and histological section of the excised nerve showed no ganglion cells. One month later the patient submitted to a sympathectomy by the anterior approach, and thereafter was free from pain.

At the second operation (by anterior approach) location of the stellate ganglion was exceedingly difficult owing to scarring following the previous operation. A large nerve filament was found which joined the first dorsal root in front of the first rib. It appeared to come up from the second or third root of the sympathetic trunk. This, together with a large fragment of tissue in the position of the stellate ganglion was resected. Histologically many ganglion cells were present in the section.

On regaining consciousness the patient volunteered that he was free from pain. His temperament underwent a great change. He became cheerful, very interested in his surroundings, and made several fast friends in the ward. He developed into a habitué of movie shows and concerts, and was unaffected by noises, excitement, or other stimuli. His hand remained dry and warm and the range of movement in his fingers increased, so that he was able to write clearly. He used the limb almost normally, and was recently seen in the ward carelessly brushing back his hair with the formerly causalgic hand. 
F. L., aged 33. A Case of the Proximal (?) Causalgic Syndrome.

Admitted four months after receiving gun-shot wounds (shell-fragments) of the left shoulder and anticubital space. He sustained a compound fracture of humerus with what appeared to be a complete ulnar and median palsy.

One month after injury following remanipulation of left humerus he noticed severe pain in left hand. He described the pain as "terrific," but could not specify its quality. It was made worse by smoking, by the noise of aeroplanes and the wireless and by jarring of his bed. He lay in bed with knees drawn up and noticed severe exacerbations when these were straightened. Stroking the feet or other contact made the pain almost unbearable. He was irritable, solitary, and always depressed ; his manner almost cringing. The pain was felt diffusely on the palmar aspect of the hand including the anæsthetic ulnar area. It had become progressively worse since the injury. Analgesic drugs failed to give relief, even in large doses and only morphia secured for the patient a few hours sleep. Otherwise the only relief he obtained was by holding a cold wet cloth in his normal hand.

The arm and forearm were œdematous and touching them increased the pain. The fingers and wrist were so stiff as to appear ankylosed. The skin on the dorsum was thin and shiny but on the palmar surface was encrusted and macerated owing to the impossibility of cleaning it.

In so far as clinical examination could be conducted it was evident that the patient had a complete ulnar and musculospiral palsy. There was definite diminution in appreciation of light touch and pin-prick in the median area with paralysis of the thenar muscles, but there was still some contraction of the long finger flexors supplied by the median nerve.

Stellate block at the fifth month with 2 per cent. procaine produced almost complete relief of pain temporarily.

Operation was delayed to the seventh month owing to condition of the wounds. Stellate ganglionectomy was then performed. Following this the patient had complete relief from his " terrific" pain, there remaining only a slight ache in the palm which the patient attributed to stiffness. The limb could now be handled without producing pain and other stimuli previously mentioned were without effect. He could smoke without pain and was able to discard his damp rag. He smiled when in conversation and was, in fact, a normal person. His fingers, of course, remained stiff, but it was now possible to initiate treatment.

A. B., aged 24. A Case of the Distal Causalgic Syndrome.

Admitted eight months after receiving a machine-gun bullet through the left upper arm, which fractured the humerus. The wound healed after only slight sepsis and the fracture united in normal fashion.

The day following the injury the hand became painful but was not swollen. The pain was situated on the palmar aspect of the hand, including the fingers and thumb and was also felt under the nails. It was extremely severe at first so that he required morphine and stated that he was " only able to live by sleeping most of the time." The pain was now tolerable, but he was not sure if this was only because he was accustomed to it. The pain was burning in character as though the hand were held in front of the fire and he could not pull it away. It was made worse by various things, but chiefly by excitement. He stated that thunder and lightning caused intense spasms of pain, and any sudden noise or seeing other patients quarrelling caused exacerbations of the pain. He was able to get relief by lying still in a quiet place. It was also eased to a certain extent by cold weather. It was made worse by anything touching the soles of his feet, as when putting his socks on, and it was also worse when he touched anything with his normal hand when it was dry, and he therefore preferred to keep this hand moist. He spontaneously remarked that drawing deeply on a cigarette caused the pain to be worse, and this also occurred when he was asked to take a deep breath.

Examination showed moderate weakness of all the muscles supplied by the ulnar and median nerves and no loss of sensation. Pin prick was felt as very unpleasant and seemed to increase the pain, while light touch was not disagreeable unless drawn across the skin. Deep pressure was painful, but the pain passed off if it was continued. The pain felt in the hand when other parts of the body were stimulated seemed to occur without delay. The pain was not diminished, but rather seemed to be increased by suprasystolic compression of the forearm.

He had noticed that the fingers had always been warm and pink and this condition was still present (Fig. 6, Exp. 1). The skin was thin but not sufficiently tight to be called glossy. There was marked atrophy of the finger tips and curvature of the nails. Sweating was profuse on the tips of the fingers and dorsum of the hand. A severe hyperextension deformity of the metacarpo-phalangeal joints was present.

X-rays showed marked decalcification probably of the Sudeck type (Fig. 7).

Block of the sympathetic trunk caused complete relief of all pain (Fig. 6, Exp. 2). Block of the ulnar and median nerves in succession caused relief of pain in their respective areas, and this relief applied to the induced exacerbations as well as the spontaneous varieties of pain.

A series of X-ray treatments to the hand resulted in no improvement.

Stellate ganglionectomy was performed by anterior

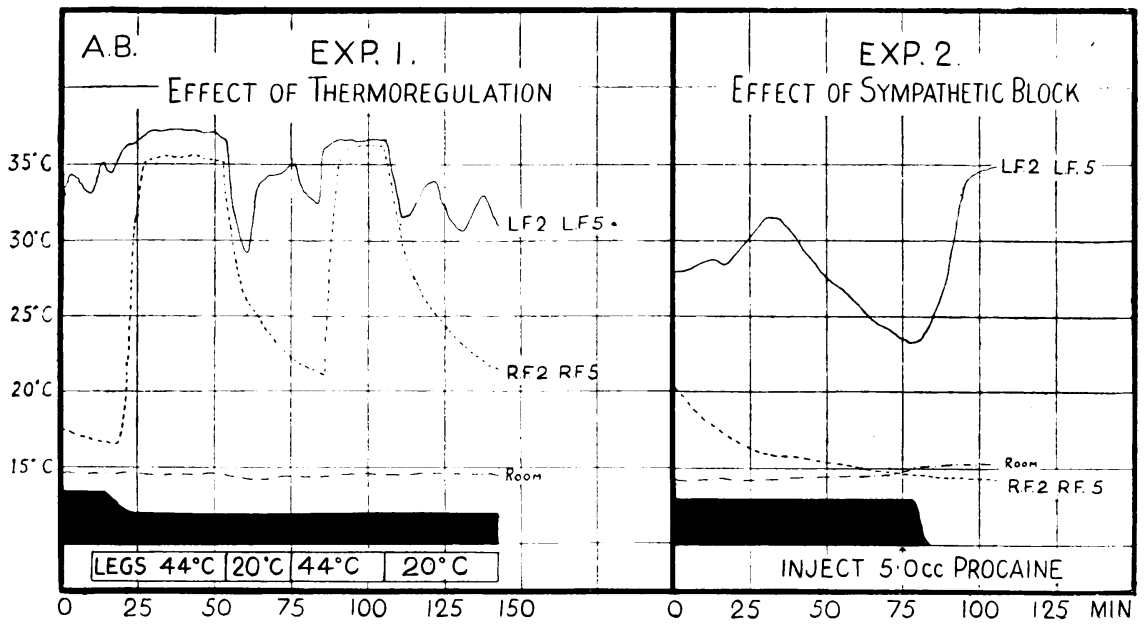

Fig. 6.-Temperature charts of subject A. B. Cónventions as in Fig. 2. 


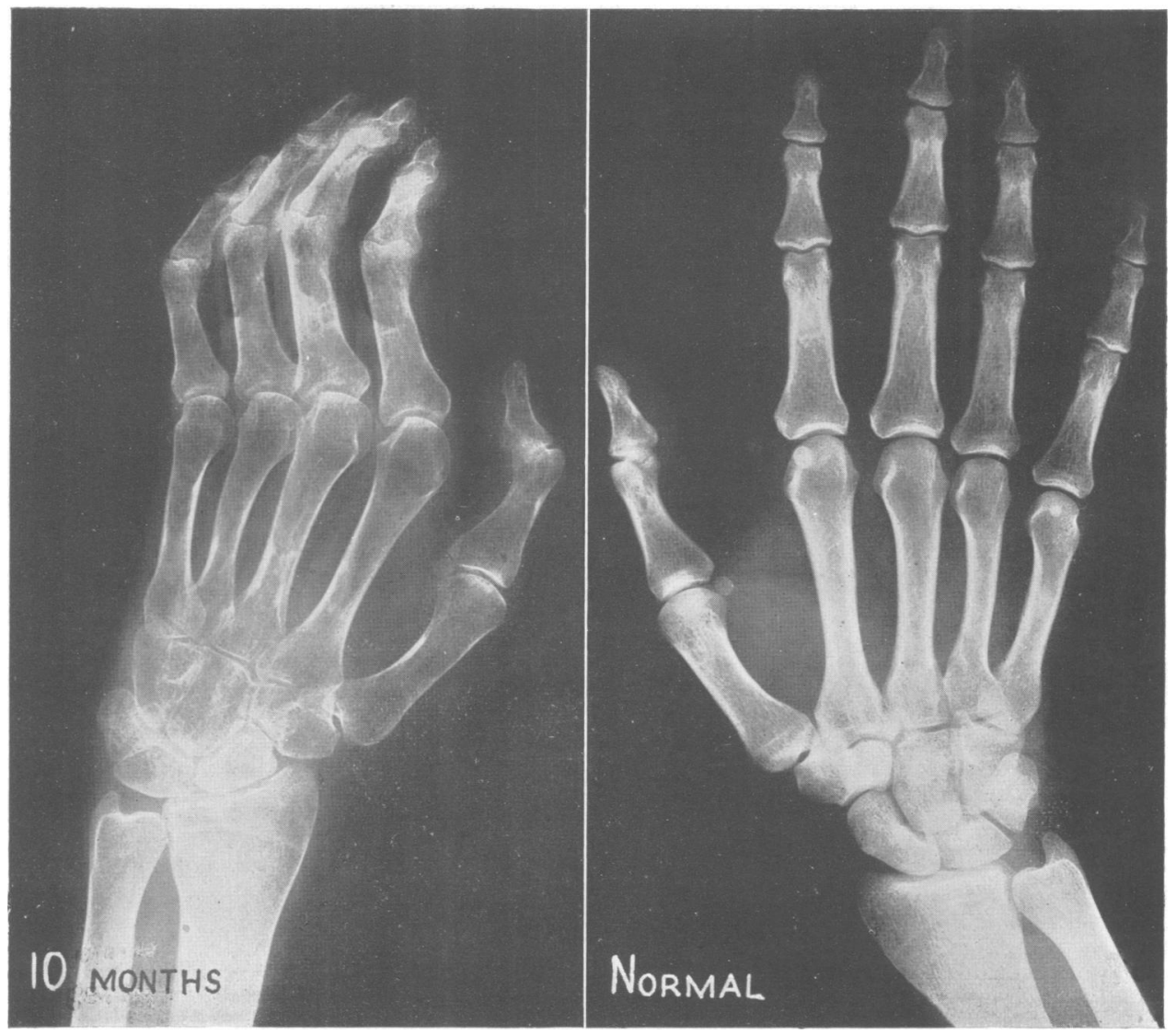

Fig. 7.-X-rays of subject A. B. taken 10 months after injury. The hands were simultaneously exposed.

approach in the fourteenth month. Following resection of the ganglion the patient developed a well-marked Horner's syndrome which for a few weeks was rather troublesome. Spontaneous pain completely disappeared after operation, and he was well able to tolerate active measures to correct the deformity. Sensation to light touch and pin-prick was normal in all areas except that there was slight paræsthesia in the median distribution.

\section{S., aged 24. A Case of the Distal Causalgic Syndrome.}

Six months before admission he received a machine-gun bullet through the soft tissues of the right arm 2 in. above the elbow. Healing of the wound occurred without infection.

Three days later pain commenced when he awoke from an anæsthetic during which the arm had been put in plaster. Within 24 hours it had become intolerable and he received morphine for relief. Since then it had become much less, but was still very uncomfortable. The pain had always been situated chiefly in the palmar aspect of the middle and ring fingers and adjoining part of the palm. Since its onset it had been of a severe aching character which he could not describe. It was increased by a variety of things, such as noise, swallowing, taking a deep breath, going to a concert, and seeing people fight. He also said that gripping with the good hand caused the pain, unless he gripped on a damp rag. The pain was worse in hot weather than in cold.

Examination showed a slight weakness of the muscles innervated by the ulnar nerve with a complete loss of sensation in the ulnar area. There was a hyper-reaction to light touches in the median nerve area, and such stimuli increased the pain.

The condition of the hand was not obviously different from that of an ordinary ulnar nerve palsy, except that the skin of the median area was thin and showed the effects of lack of use. Temperature records for a period of 2 hours were not obviously different from those of an ordinary ulnar nerve lesion (Fig. 8, Exp. 1). Sweating

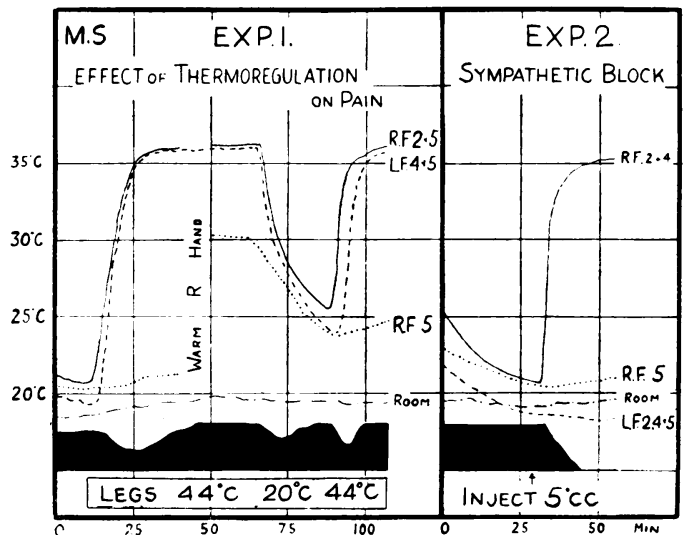

FIG. 8.-Temperature charts of subject M. S. Conventions as in Fig. 2.

was slightly more profuse in the median area than in the normal and was absent in the ulnar area.

X-rays showed decalcification of indefinite type.

Sympathetic block caused complete relief of pain (Fig. 8, Exp. 2).

Block of the ulnar nerve at the wrist caused no change in the hand except a palsy of the ulnar innervated muscle. Block of the median at the wrist caused complete relief of all pain and discomfort. 
X-ray treatment to the median nerve at the level of the lesion caused no relief except some tenderness in this region was abolished. Two weeks later a further course of treatment was given to the hand with no benefit.

In the eighth month the nerves were explored. The median appeared normal, while the ulnar was almost completely divided. Resection and suture of the ulnar was performed and the nerves placed in a fresh bed. He was free from pain for four days, but then the pain returned with greater intensity than ever.

One month later repeat block of the stellate ganglion with 2 per cent. procaine (10 c.c.) gave complete relief of pain. The hyperæsthesia and tenderness of the palm were also relieved.

In the ninth month stellate ganglionectomy by the anterior approach with resection of the second ganglion produced a mild Horner's syndrome. Since operation the patient has been absolutely free of pain and the hyperæsthesia has not returned. He now has a full range.of movement in his fingers and use of the hand is limited only by the ulnar nerve lesion.

W. A., aged 25. A Case of the Distal Causalgic Syndrome.

Three days before admission he was accidentally shot through the right axilla. Immediate operation had disclosed that the axillary vein was divided and this was ligatured; the artery was intact. The condition of the nerves was not determined.

On admission he complained of a throbbing pain in the wound and there appeared to be a complete block of the median, ulnar and musculospiral nerves. One week after the injury he began to have an aching pain down the ulnar side of the forearm extending into the palm of the hand. This was fairly constant, but at times would disappear for a few minutes, and it was sufficiently severe to prevent more than two or three hours sleep. This pain disappeared in the course of two to three weeks. About six weeks following injury, the sensation began to return to the median and musculospiral areas, with a concomitant return of muscular power. No sign of function was found in the ulnar nerve. At this time the patient began to complain of a burning searing pain in the part of the hand to which sensation had returned. This pain was very severe, and its depressing effect was very apparent on the face of the patient, which became haggard and careworn. The pain was aggravated by any' attempt to move the hand or wrist and by even the lightest touch over the median nerve. It was relieved by keeping as quiet as possible and avoiding excitement. When asked about the cinema he reported that he had to close his eyes during the action scenes in order to lessen the pain. At this time slight hyperhydrosis of the median area was present and because of the fixed position of the hand the skin was macerate 1 and did not present the appearance of " glossy fingers." There was moderate odema and limitation of movement at all the joints.

X-rays showed marked evidence of Sudeck's atrophy (Fig. 9).

At the third month after injury there being no signs of improvement in the pain nor any return of function to the ulnar nerve, the brachial plexus was explored by Mr. R. Barnes. The median nerve appeared normal and was only involved in the thinnest scar tissue. The ulnar nerve was found divided and required suture. The axillary vein was represented by a fibrosed cord while the artery appeared normal. A peri-arterial sympathectomy was performed by stripping the adventitia off the vessel for a distance of $5 \mathrm{~cm}$.

After operation the pain was diminished for approximately one week and then returned to its former intensity, still being felt only in the median area.

The sympathetic chain was blocked twice in the fifth month with good, but only temporary, relief. Block of the median nerve at the wrist abolished all pain in the hand.

A series of X-ray treatments was given to the hand in the sixth month and approximately 7 to 10 days later he began to improve. In the ensuing two weeks further improvement occurred so that though he was not free from pain, he looked less careworn and the hand could be handled much more freely. Improvement thereafter was continuous though slow, and there remained much pain on attempting to move the stiff joints. At the end of the twelfth month he was sufficiently recovered to be able to return to his work as a shoemaker, but still experienced slight pain associated with emotional excitement. When last seen at the twenty-fourth month, all the muscles innervated by the ulnar nerve were contracting, there was only a vestige of pain, though still considerable limitation of joint movement and the X-rays show recalcification of the porotic bones.

\section{W. E., aged 32. A Case of the Proximal Causalgic Syndrome in a Phantom Limb.}

One year before admission the patient was wounded in action and disarticulation of the right arm at the shoulder was performed 24 hours later. He also sustained compound fractures third, fourth, and fifth fingers of the left hand.

Two to three weeks after injury pain began to be felt in the phantom right hand. This was a tight sensation at the base of the thumb and a severe searing sensation in the ring finger, though the whole hand was affected to a moderate degree. There had been little change in it since it first developed. The pain was nearly constant, but was greatly aggravated by any excitement. As an illustration he told how the pain became almost unbearable if when the train in which he was riding suddenly passed another going in the opposite direction. It was also ascertained that a sudden noise made experimentally caused a marked increase in the pain. It was found that a deep breath caused a momentary exacerbation of the pain.

Examination showed the stump to be in good condition and the scar well healed. In one place, however, on the anterior aspect pressure on the scar caused a pain to shoot down the phantom limb and at the same time the pain in the hand became worse.

Experimental procedures were necessarily restricted to observing the effect of procaine block of the stellate ganglion. This produced complete relief of pain, which preceded the development of a Horner's syndrome by several minutes. This procedure was repeated on three occasions with only temporary relief. Circumstances beyond the patient's control prevented a sympathectomy being done.

\section{R. D., aged 52. A Case of Dystrophic Pain.}

Three weeks before admission was wounded in the right axilla by a bomb splinter. At immediate operation the median nerve was found frayed, the ulnar nerve was divided, and it was sutured, while the brachial artery and vein had lateral holes. These vessels were divided and ligated.

Pain commenced when he recovered from the anæsthetic and had been present ever since as a severe aching in the distribution of the median nerve. It was a constant crushing sensation, made worse by letting the arm hang down or attempting to move the fingers and was also worse at night. It was not affected by emotional stress, loud noises, or other such stimuli. There was moderate swelling of the hand, reduced sweating and fixation of the joints. The œdema and joint affection were equally prominent in the ulnar distribution. Skin temperatures recorded at various times were not obviously different from those of an ordinary ulnar nerve lesion (Fig. 10), while oscillometric tracings from the forearms showed a greatly reduced pulsation on the affected side.

An exploration was performed by Mr. A. S. Kerr at the third month. The median nerve was found to be involved in slight scar tissue while the ulnar was the seat of a neuromatous formation, but regeneration appeared to be progressing. The brachial vessels could not be defined, and after neurolysis the wound was closed.

The condition remained unchanged until about the 

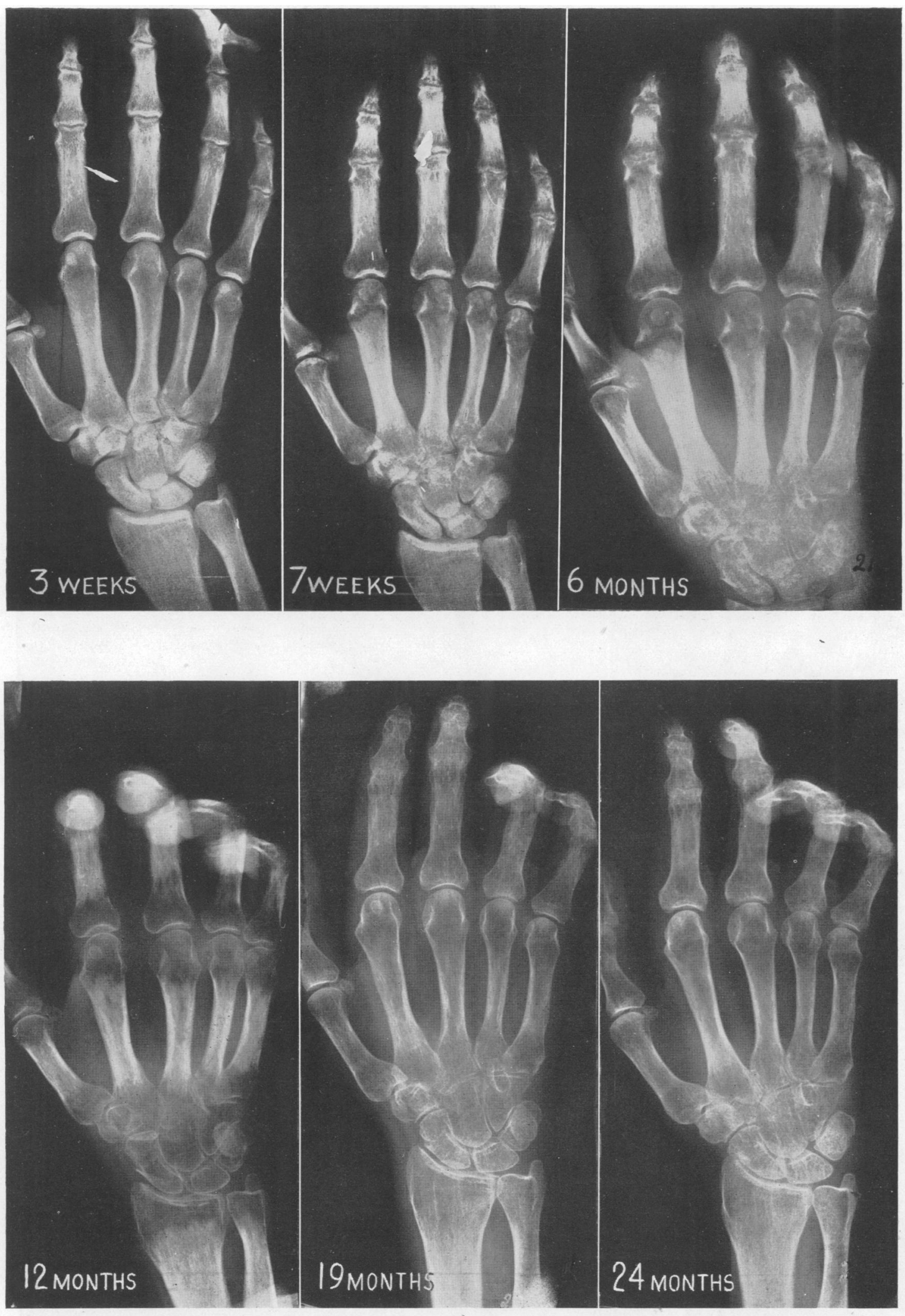

Fig. 9.-X-rays of subject W. A. taken at the times indicated after injury. That taken at the third week was in no way different from the normal exposed at the same time and not reproduced here. 


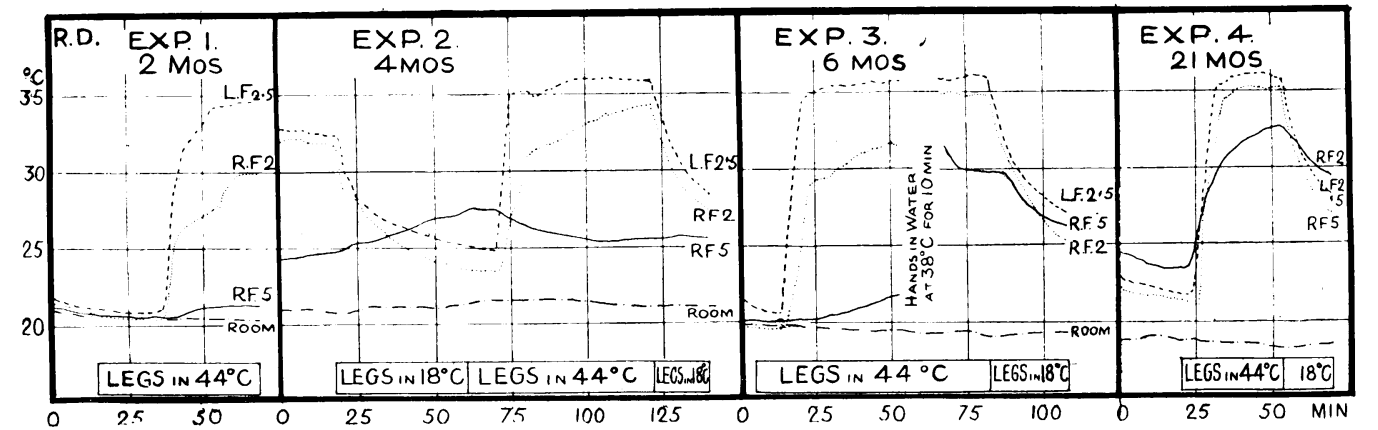

Fig. 10.-Temperature charts of subject R. D. Conventions as in Fig. 2. During the experiments the pain was slight and the patient's statements inconsistent.
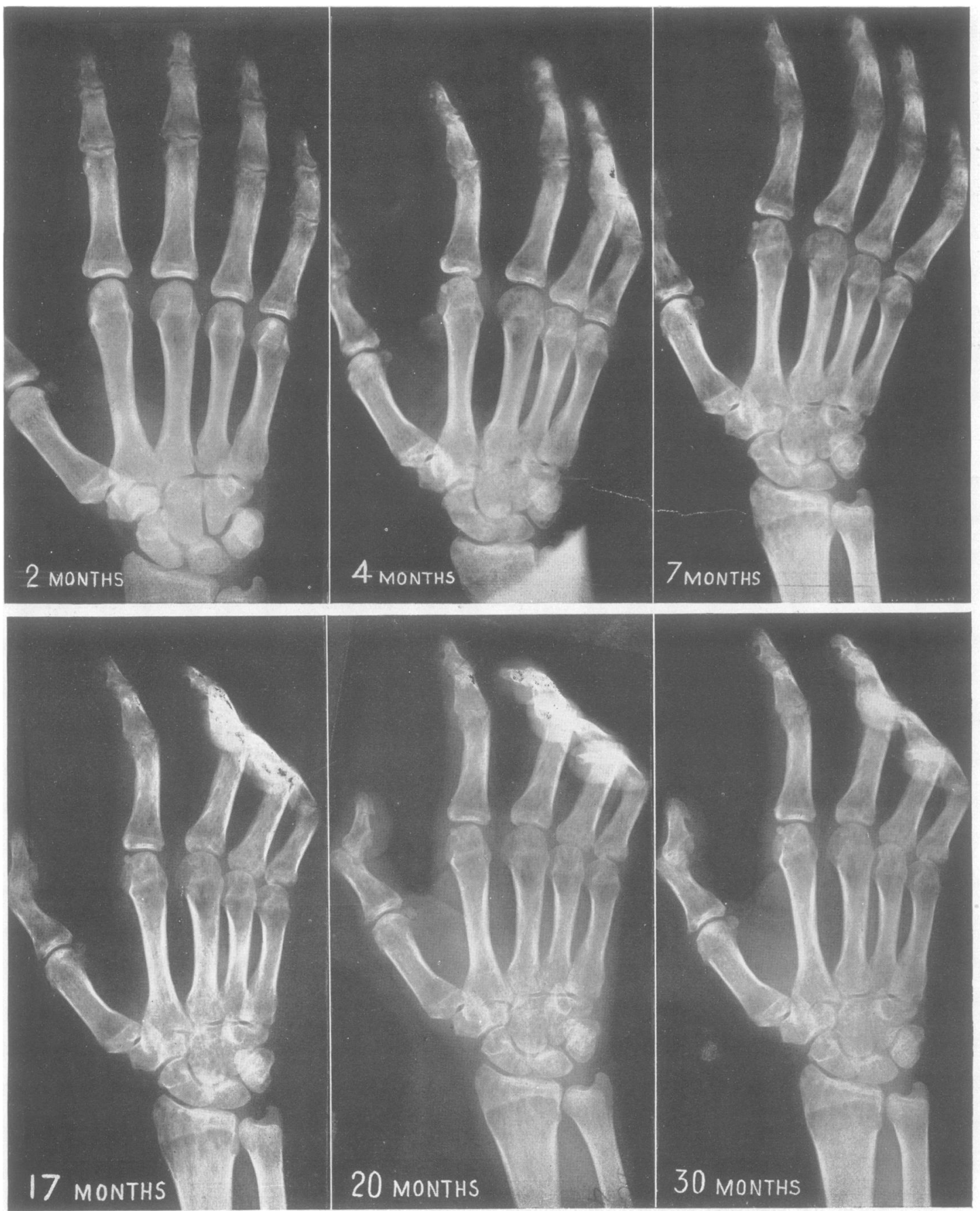

FIG. 11.-X-rays of subject R. D. taken at the times indicated after injury. That taken at 2 months was in no way different from the normal exposed at the same time and not reproduced. 


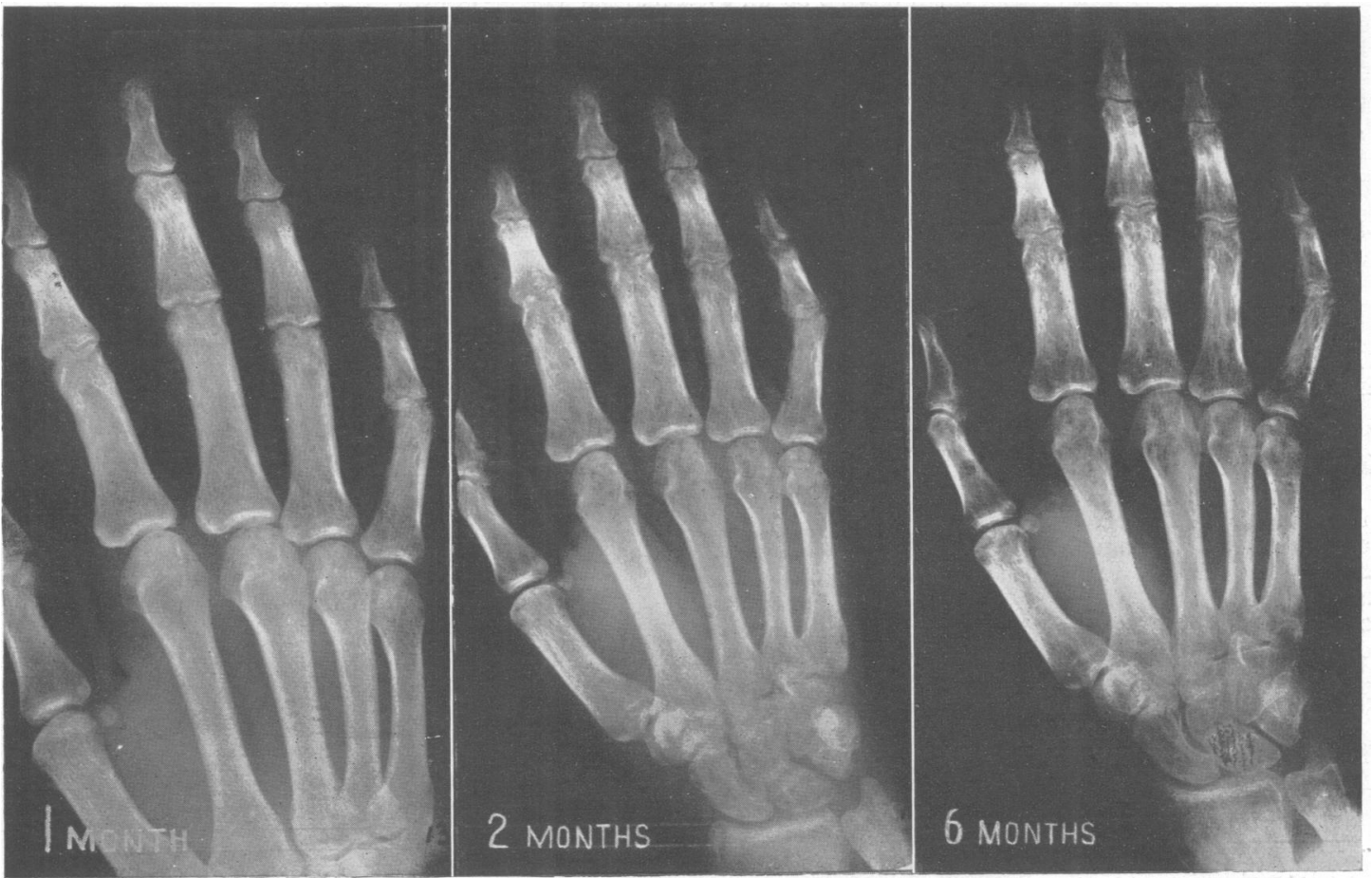

Fig. 12.-X-rays of subject W. C. taken at the times indicated. That taken at 1 month showed little difference from the normal exposed at the same time and not reproduced here. .

fifth month, when pain began to get less. At this time the œdema had disappeared and the skin was very tense and shiny.

X-rays showed well-developed Sudeck's atrophy (Fig. 11).

A clue to the nature of this patient's disability was now obtained for he complained bitterly about the sensations aroused from the regenerating end of the ulnar nerve. These sensations seemed to loom as large in his consciousness as did the pains attributed to the dystrophic changes so that it became a matter for speculation as to whether he was not unduly pain susceptible.

\section{W. C., aged 41. A Case of Bystrophic Pain.}

One month before admission fell and fractured the right humerus, which was associated with a lesion of the musculospiral nerve.

Following the injury he said that he had moderate pain in the back of the hand for two weeks. This was usually noticed for 1 hour after he went to bed.

At the time of admission he complained of no spontaneous pain, but heavy pressure on the dorsum of the hand or full extension of the fingers was painful. The hand was moderately swollen and had been supported on a straight finger splint. The musculospiral nerve palsy was recovering. The further course was uneventful, except that at the fourth month he refractured the humerus and thus required further care in hospital. Physiotherapeutic treatment restored movement to the joints. In the next few months he occasionally complained of odd aching sensations in the hand and those were most in evidence at night.

X-ray showed definite osteoporotic decalcification of the carpus (Fig. 12).

\section{F. B., aged 32. A Case of Dystrophic Pain.}

Three months before admission he sustained a fracture of the right tibia and fibula, which was treated in plasterof-paris.

On admission the plaster was removed and the fracture appeared firmly united. On attempting to commence weight bearing the patient complained of an aching pain in the foot. There was no obvious limitation of movement and no tenderness on pressure, but X-rays showed a definite spotty decalcification (Fig. 13).

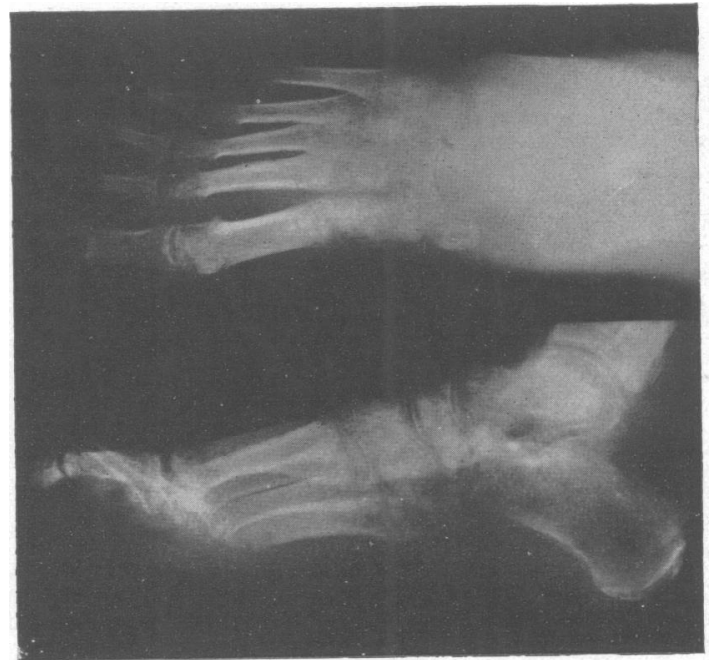

Fig. 13.-X-ray of subject F. B. 3 months after injury.

In the course of the next month the pain diminished and only recurred on walking long distances.

\section{R. L., aged 31. A Case of Psychogenic Pain.}

Six months before admission he sustained multiple wounds of the back of the right thigh by fragments from an explosive cannon shell. 
He stated that 4 to 5 days after the injury he began to have a severe aching pain in the right foot, which prevented sleep for two months. It was steady in character, comparable to a toothache, and was situated on the dorsum of the foot. He knew of nothing that relieved it, though radiant heat made it worse. He had received ionization treatment to the scars on the thigh without benefit. This pain had persisted and was severe, but did not prevent him walking, but it prevented him doing physical training. It was worse at night when trying to get to sleep, but was less noticeable when at the cinema.

Examination showed no abnormality of the foot. The pulses were equal and there was no limitation of movement, nor was there any disturbance of sensation. There were many metallic foreign bodies in the thigh, but they were not associated with any tenderness.

X-rays of the feet showed no rarefaction.

He was at first accepted as being quite genuine and in this spirit preparations were made to test the effect of lumbar sympathetic block. Shortly after the insertion of the needle and before the injection of the anæsthetic, he became free of pain for the first time since injury. However, in another two to three minutes the foot became numb and useless, in particular he noticed that he could not flex his toes. Nevertheless, a well-marked flexor response to plantar stimulation was easily obtained. It now became quite clear that this was a case of hysteria and he was told that the numbness would pass off in 2 to 3 hours and he would thenceforth be free of pain. The following day he was free of pain, but complained of tingling feelings when walking.

\section{P., aged 25. A Case of Osteoporosis and Hyper-} hydrosis without Pain.

Ten months before admission he received a wound from a machine-gun bullet causing a compound fracture of the lower end of the radius and the ulna and a median nerve injury of the right arm.

On admission he was found to have chronic osteomyelitis of the radius with non-union of the fractures, marked osteoporotic changes in the bones below the level of the lesion (Fig. 14) and a complete lesion of the median and radial nerves. The condition of the index and middle finger qualified for the description of glossy fingers. The skin was thin and tight so that all the creasings and markings were nearly obliterated. The nails were extraordinarily curved and thickened, and the digits were tapered almost to a point. The temperature of the two sides of the hand varied, but usually the median nerve area was cold; sweating in the ulnar area was excessive but was absent in the median and radial areas. At intervals of some months crops of vesicles would appear on the hand irrespective of the nerve distribution and in the ulnar areas they caused an itchy sensation.

Despite all the objective signs of causalgia this patient had no pain.

The subsequent course was not noteworthy. Under appropriate treatment the osteomyelitis was cured and the fracture healed. Otherwise at the end of 30 months there was little change, the hand being of use only to steady light objects.

\section{Discussion}

In commenting on these patients it is helpful to consider that post-traumatic pains may be produced by several different mechanisms. On this basis the pains may be divided into three groups: (1) psychogenic, (2) causalgic, and (3) dystrophic. The significance of the first two terms is self-evident, while the term dystrophic has been selected, not because it is non-committal, but because it seems to express the view that the pain is secondary to a disturbance of nutrition in the extremity. A brief note may be ventured on each of these three types without attempting exhaustive discussion.

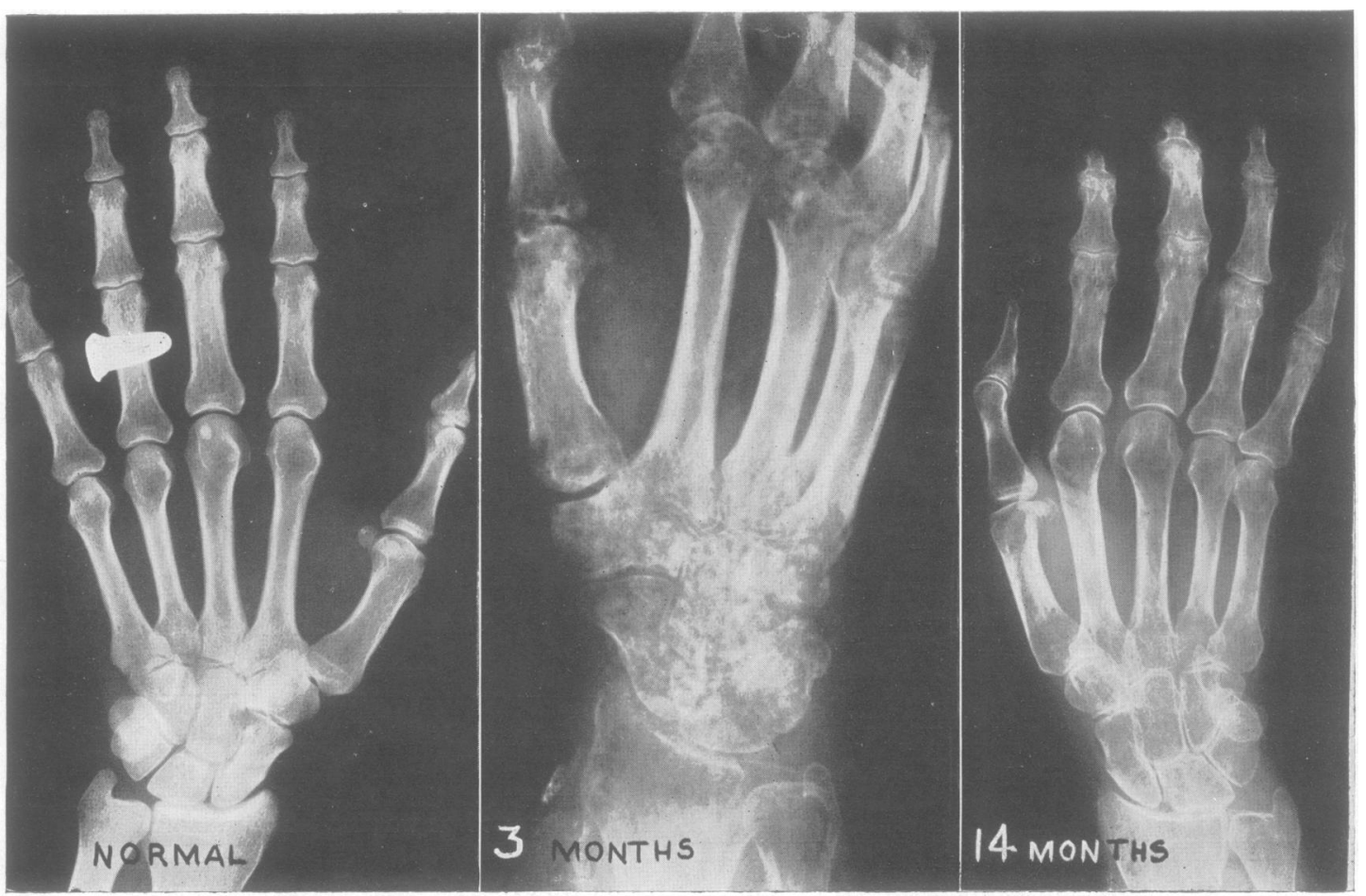

FIG. 14.-X-rays of subject D. P. taken at the times indicated after injury. The normal left hand was exposed at the same time as the right at 14 months. 
1. Psychogenic.-Case R. L. suffered from pain of this type as shown by the therapeutic efficacy of a mock attempt to block the sympathetic chain. There was also other evidence of the liability of this patient to develop hysterical manifestations. Such cases were easily distinguishable from those of the causalgic syndrome, but failing the aid of the therapeutic test they might well have been confused with the dystrophic group. This particular patient, however, showed no sign of trophic disturbance, but if such had developed due to disuse as has been shown possible by Hurst (1940) the diagnosis would have been difficult. In fact it is not unreasonable to suppose that genuine dystrophic pain might supervene under these circumstances.

2. Causalgic.-This group consists of cases T. P., E. M., F. L., A. B., M. S., W. A., W. E., and H. G., whose pains were essentially of the one type, and this conformed to that described above as causalgic. Moreover, it is apparent that two groups of patients with the causalgic syndrome may be distinguished depending on whether the pain originates at a proximal or distal site as determined by peripheral nerve block. Thus for fuller diagnosis the term causalgic syndrome should be modified by either the adjective proximal or distal to denote the site of cross-stimulation. For complete diagnosis further enquiry will be necessary so that the conditions predisposing to the linkage of the sympathetic and sensory fibres may be stated. Of these it is not unlikely that vasospasm and ischæmia may play a part, a consideration which would explain the relatively high incidence of causalgic pain in injuries involving the root of the limb.

Attention should be drawn to the fact that many of the cases described here were not seen until several months after injury. Therefore, the descriptions of the initial symptoms depend on the memories of a period confused by fatigue, shock, and narcotics and may not be entirely reliable. However, taken at their face value they suggest that in the initial stages the severity of the pain may be too disconcerting for the patient to recognize the various features which characterize causalgic pain.

3. Dystrophic Pain.-Cases R. D., W. C., and F. B. exhibited pain of this type, which was typically of a dull aching character made worse by movement of the part and, in common with osteoarthritic pains, tended to be most in evidence at night. It is tentatively suggested that this pain is secondary to disturbance of nutrition consequent on any of the factors disturbing the environment of the tissues. These factors will include disuse, defective arterial supply, defective venous drainage, and defective lymphatic drainage. To imagine that there is also some individual predisposing factor to the development of dystrophic changes need not unduly strain the hypothesis; witness the wide range of subclinical peripheral circulatory disorders such as postural œdema, mild vaso-spastic stat 2 ; and mild erythrocynosis; witness also the possibilities of individual variations in the buffering capacity of the blood and tissue fluids which would modify the nutritional changes. This conception of the varied factors causing dystrophic changes seems not only to be in accord with the facts, but in agreement with the views of Gordon (1934) and Frutiger (1939). It obviates the necessity of searching in these cases for some common factor, such as vasospasm or vasodilatation. It is not out of place to remark that the researches of de Takats (1943) on patients who apparently fall into this group, show that there is a tendency to an increased blood-flow in the affected extremities, but it yet remains to be shown whether this is a cause or an effect or merely a coincidental phenomenon such as would result from a slight interference with the vasoconstrictor nerves.

If such a view of the development of dystrophic changes which are characterized by œdema, bone resorption, and periarticular fibrosis be correct, it is easy to assume that these changes might give rise to pain. This pain, moreover, would likely be of the type described by these patients.

One puzzling feature which presents itself is the great disparity in the severity of the pain complained of by different patients. For this two explanations which are not mutually exclusive may be advanced. In the first place there may be in some cases an element of peripheral neuropathy, secondary to the nutritional disturbance of the limb, giving rise to dysæsthesia distorting the ache into an agonizing pain. Evidence for this might be found in the disturbances of cutaneous sensation which are frequently described. In the second place there is good reason to believe that there is much psychogenic exaggeration of the pain in the most severe cases. Here the analogy to cases of post-traumatic headache is too close to be lightly dismissed. Not only is the hand of similar emotional significance as the head but the two types of case are similar in age incidence, frequency of compensation proceedings, and in their response to a variety of therapies in the hands of different proponents. In regard to the latter reference may be made to treatment by periarterial sympathectomy (Herrmann and Caldwell, 1941), X-ray (Mumford, 1938), physiotherapy (Henderson, 1936), carbaminoylcholine ionization (Middleton, 1937), alcohol injection of nerves (Turner, 1936; Little, 1939), and typhoid injection (Cravener, 1936). It is not the intention to impugn any one of these modes of therapy, but to endeavour to show that as in a case of chronic post-traumatic headache, so in one of post-traumatic dystrophic pain there is not only some cause to doubt the organic basis of a disabling symptom, but also leeway for major differences of opinion between clinicians.

In conclusion, it may be said that a diagnosis of dystrophic pain should include not only an assessment of the psychogenic element, but also an indication of the factors responsible for the dystrophy. One may hope that such an ideal may soon be attainable.

Summary

It was noted that there was a need for a clearer definition of post-traumatic pain. 
An attempt has been made to define the causalgic syndrome, using as a basis a theory of the mechanism of production of the symptoms.

This theory ascribed the peculiar qualities of causalgic pain to stimulation of sensory fibres by efferent impulses in the sympathetic fibres.

Evidence in favour of such a linkage was obtained from a study of the reactions to a variety of stimuli and from the results of peripheral nerve, nerve root, and sympathetic chain block.

Two types of causalgic syndrome were described depending on whether the site of conjunction of the sympathetic and sensory fibres was proximal, i.e. at the site of the nerve lesion or distal, i.e. near the terminations of the fibres.

It was considered possible that the distal type could occur as a result of some disturbance of metabolism due to œdema, ischæmia, or some other factor determined by injury to the limb as opposed to a primary injury to the nerve trunk.

A series of cases exhibiting post-traumatic pains was reported, and these were grouped under the terms psychogenic, causalgic, and dystrophic.

Comment was made on the vascular and nutritional changes with particular reference to osteoporosis. This reaction was considered to be nonspecific, and it was shown to occur independently of the peripheral nervous system.

\section{REFERENCES}

Bolton, B., Carmichael, A. E., and Stürup, G. (1936). J. Physiol, 86, 83.

Carmichael, E. A., Honeyman, W. M., Kolb, L. C., and Stewart, W. K. (1941). Ibid., 99, 329.

Cravener, E. K. (1936). New York State J. Med., 36, 815.

Delorme, C. (1917). Bull. Acad. Med., 77, 577.

Doupe, J. (1943). J. Neurol. Psychiat., 6, 94.

Doupe, J., and Cullen, C. H. (1943). Ibid., 6, 113.

Fontaine, R., and Herrmann, L. G. (1933). Ann. Surg., 97, 26.

Frutiger, U. (1939). Helvetica med. Actx., 6, 480.

Gordon, D. (1934). Ann. Surg., 99, 623.

Gurd, F. B. (1934). Ibid., 99, 449.

Henderson, M. S. (1936), Minnesota Med., 19, 214.
Herrmann, L. G., and Caldwell, J. A. (1941). Ann. Surg., 51, 630.

Herrmann, L. G., Reineke, H. G., and Caldwell, J. A. (1942). Amer. J. Roentgenol., 47, 353.

Homans, J. (1939). Circulatory Diseases of the Extremities, p. 136. The Macmillan Co., New York.

Hurst, A. (1940). Medical Diseases of War, p. 23. Edward Arnold \& Co., London.

Katz, B., and Schmitt, O. H. (1942). J. Physiol., 100, 369.

Kienbock, R. (1901). Wien. med. Wschr., 51, 1346.

Leriche, R., and Fontaine, R. (1929). Lyon Chir., 26, 323. (1930). Presse méd., 37, 617.

Lewis, T. (1942). Pain, p. 91. The Macmillan Co., New York.

Lewis, T., and Pickering, G. W. (1931-33). Heart, 16, 33.

Little, N. (1939). Med. J. Anat., 1, 263.

Medical Research Council (1920). Spec. Rep. Series No. 54, p. 53.

Middleton, O. S. (1937). Glasgow med. J., 127, 119.

Middleton, O. S., and Bruce, J. (1933-34). Ed. med.chir. Soc. Trans., 113, 49.

Miller, O. S., and de Takâts, G. (1942). Surg. Gynec. Obstet., 15, 558.

Mitchell, S. W. (1872). Injuries of Nerves and Their Consequences, p. 196. J. B. Lipincott \& Co., Philadelphia.

Mitchell, S. W., Morehouse, G. R., and Keen, W. W. (1864a). Gunshot Wounds and the Injuries of Nerves, p. 104 . J. B. Lipincott \& Co., Philadelphia. (1864b). Ibid, p. 147.

Mumford, E. B. (1938). J. Bone Jt. Surg., $20,949$.

Noble, T. P., and Hauser, E. D. W. (1926). Arch. Surg., 12,75 .

Nonne, - (1902). Fortschr. geb. Roentgenstraklen, 5, 293.

Paget, S. (1864). Med. Times, Lond., -, 331.

Pollock, L. J., and Davis, L. (1933). Peripheral Nerve Injuries, p. 47. Paul B. Hoeber, New York.

Spiedel, C. C. (1935). J. comp. Neurol., 61, 1.

Stürup, G., Bolton, B., Williams, D. J., and Carmichael, E. A. (1935). Brain, 58, 456.

Sudeck, P. (1938). Arch. klin. Chir., 191, 710.

de Takâts (1943). Arch. Neurol. Psychiat., 50, 318.

Tinel, J. (1918). Rev. Neurol., 33, 79.

Turner, H. (1936). J. Bone Jt. Surg., 18, 581.

White, J. C., and Smithwick, R. H. (1943). The Autonomic Nervous System. 3rd. Edition, p. 230. H. Kimpton, London.

Wilkins, R. W., Doupe, J., and Newman, H. W. (1938). Clin. Sci., 3, 403 .

Young, J. Z. (1944). Personal Communication. 